\title{
Tectonic and volcanic forcing on fluvial systems: two case studies from Hokkaido, Japan
}

Thomas Parkner ${ }^{1}$ and Mio Kasai

\begin{abstract}
Two case studies from Japan demonstrate that tectonic and volcanic forcing notably increased the sediment flux in fluvial systems. Therefore fluvial system studies in geomorphically active regions should also consider such forcings alongside land use and climate considerations.
\end{abstract}

Land use and climate impacts are frequently studied as the main modulators of fluvial systems since the onset of agriculture (Wasson 1996). However, in geomorphically active regions such as along the Pacific Rim human impacts are modulated by tectonics and volcanic eruptions. In two case studies from Hokkaido, the northern Japanese island (Fig. 1), we investigate the impacts of geomorphic factors on human-impacted river systems. In the Saru River system, fragile lithology and steep slopes have resulted in a dynamic sedimentary system with high natural sediment flux, which is sensitive to tectonic impact. In contrast, the sediment dynamics in the Bibi River system, our second case study, is strongly influenced by volcanic impact due to its vicinity $(15 \mathrm{~km})$ to the caldera of an active volcano.

\section{The island of Hokkaido}

The landscape of Hokkaido is shaped by active plate tectonics. The central part of the island consists of erodible metamorphic rock and hills with steep slopes. In addition, active volcanism causes pyroclastic flows and debris avalanches, regularly covering large parts of the island with tephra (Furukawa et al. 1997; Machida and Arai 2003).

Immigration to Hokkaido started with the end of Japan's isolation policy in AD 1868. Before then, land use was limited to small areas along the coast, and to lowland rivers and lakes (Imai 1975). The rest of the island was inhabited by the indigenous Ainu people, who relied dominantly on salmon fishing and deer hunting. After AD 1900 the area of cultivated land increased rapidly (Imai 1975). European style farming and industrialization were introduced and large areas of wetlands and forests were converted into paddy fields, crop fields, dairy farms and urban areas.

Outback mountain areas, despite their almost intact forest cover, are frequently subject to landslides. They are triggered by episodic storms in summer and autumn or by spring melt events. The resulting high sediment supply rates from hillslopes lead to increased sediment storage in rivers.

\section{Case study Saru River}

The high sediment flux of $470,000 \mathrm{~m}^{3} \mathrm{a}^{-1}$ on average in the upper Saru River catchment (1350 $\mathrm{km}^{2}$ ) in the Hidaka Mountain Range is strongly controlled by catchment lithology, steep slopes (highest peak reaches $2052 \mathrm{~m}$ ) and high average annual precipitation $(1350 \mathrm{~mm}$ in Hidaka; Fig. 1). Most of the mountainous area is covered by forest (87\% in 2006). Agriculture is mainly limited to the alluvial floodplain, where intense storms occasionally cause landslides and flood disasters. For the purposes of flood protection, water utilization and power generation, the Nibutani dam reservoir (Fig. 1) was completed in 1997. But rapid sediment delivery from the headwaters had already filled $85 \%$ of the reservoir's initial storage capacity by 2011 .

Deep-seated and shallow landslides dominate in the mountain areas. Deep-seated landslides, common on sedimentary and serpentine rocks, are characterized by slow but steady movement in the order of several meters per year, depending on ground water conditions. The sliding planes are often located more than ten meters below the ground and associated with deeply weathered rock layers. In contrast, shallow landslides are only a few meters deep and frequently occur on crushed basalt rocks. Their temporal activity is more episodic and caused by rainfall events. Different from deepseated landslides, they often stop producing sediment after a few years.

The last major storm in 2003 caused numerous landslides and aggradation throughout most of the course of Saru River. Elevation models for 2006 and 2010 derived from LiDAR remote sensing data show that the channel bed degraded rapidly over this period. The specific sediment loss (i.e. sediment loss per catchment area) along the river reaches was strongly related to their average channel bed slope, which is largely determined by the hardness of the underlying rocks. On the other hand, stream power $\Omega$ (the product of catchment area and bed slope), largely determined the specific sediment gain (i.e. sediment aggradation per catchment area). When $\Omega$ was $<0.72 \mathrm{~km}^{2}$, more sediment was deposited in reaches where deep-seated landslides dominated in tributary

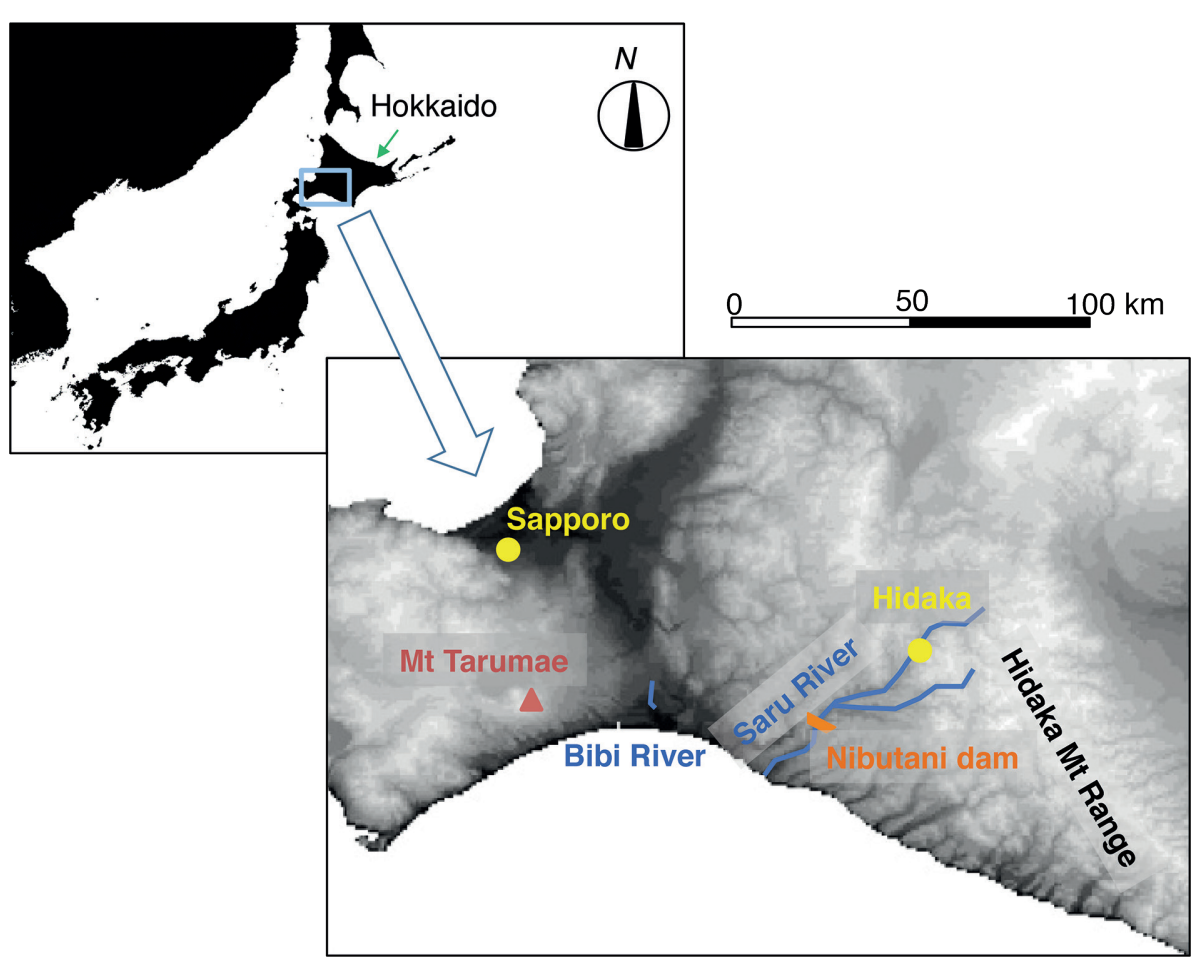

Figure 1: Location map of Hokkaido (inset) and the studied Saru and Bibi River. 


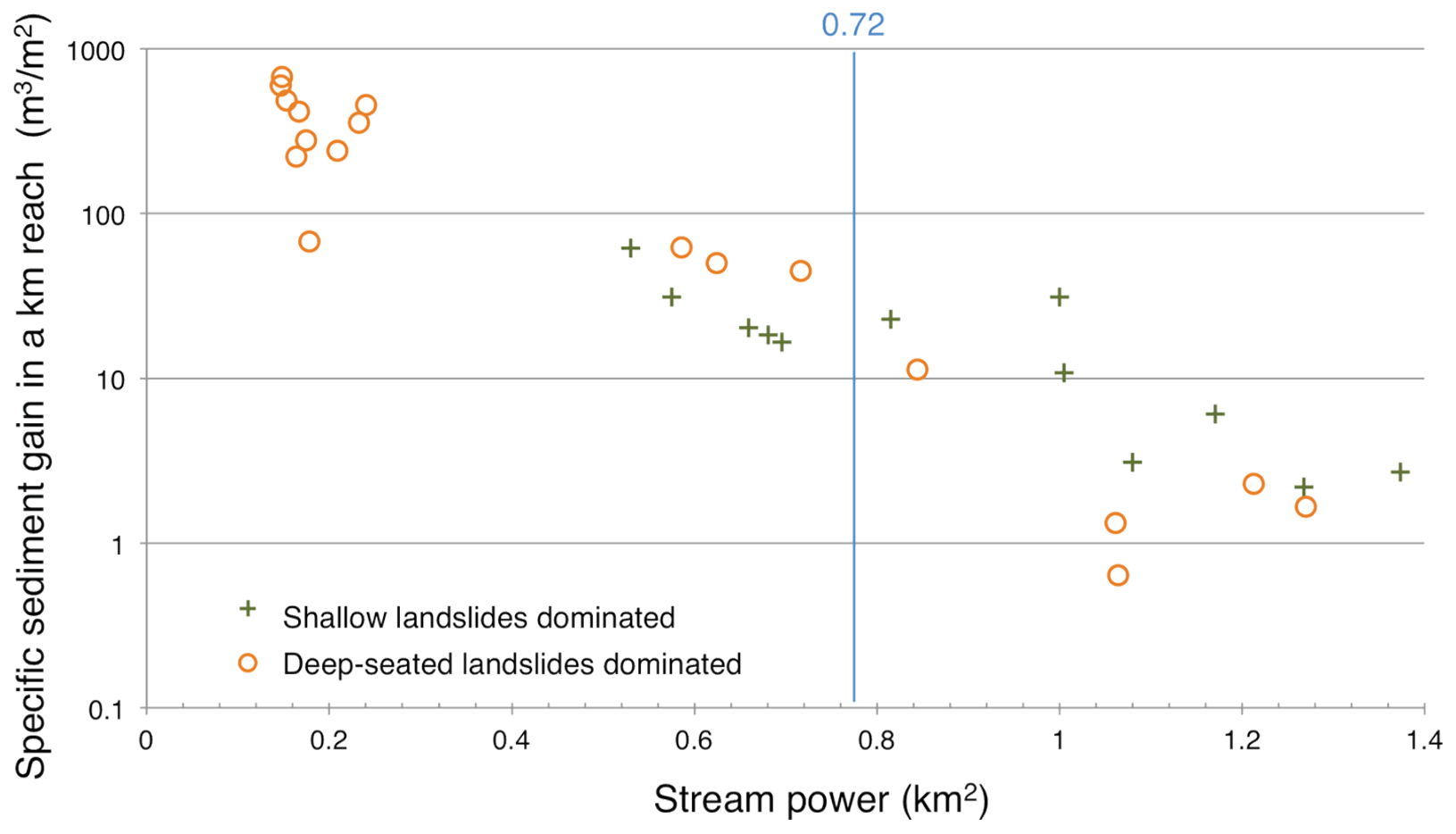

Figure 2: Relationship between stream power and specific sediment gain in a channel reach. Reaches were grouped according the dominant landslide type (i.e. deep-seated vs. shallow landslides) in their tributary catchments.

catchments compared to the reaches where shallow landslides dominated (Fig. 2). This relationship was inversed for $\Omega>0.72 \mathrm{~km}^{2}$. These results imply a balance between continuous sediment supply from deep-seated landslides and the rivers' capacity to flush out sediment. We conclude from this study that lithology-driven differences in landsliding processes and sediment production effectively control the volume of fluvial sediment transport.

In line with our results, Simizu (1998) indicated that sediment production in the headwater basin has been high at the almost same rates over the past 8,000 years. Local place names in the Ainu language (such as Shishirimuka, the Ainu name of the Saru River meaning choked with too much sediment) also suggest that the Saru River system was always characterized by abundant sediment transported. These evidences highlight the significance of tectonic activity alongside human and climatic impacts in similarly dynamic fluvial systems.

\section{Case study Bibi River}

The 17 km long Bibi river system (Fig. 1) has been impacted by human activity and volcanic eruptions over the last 3,000 years. The catchment consists mainly of volcanic sequences from the active Shikotsu-Tarumae complex, with a floodplain forming on a flat mid-Holocene coastal plain. The eastern part of the catchment was continually used for agriculture since the beginning of the last century.

The impact of human activities and volcanic eruptions on the area was studied by means of six sediment cores from the floodplain. To distinguish between air-fallen tephra and fluvial sediment, the dry density, loss-on-ignition and grain-size data of each core was compared with standard tephra stratigraphies (Furukawa et al. 2003).
Three air-fall tephra layers from nearby Tarumae volcano from 1736 AD, 1667 AD and ca. $1000 \mathrm{BC}$, correspond to a total of 2.7 Mt tephra deposition on the floodplain. The tephra deposits devastated the floodplain, covering it as thick as $60 \mathrm{~cm}$. The thickness of the purely air-deposited (non-reworked) tephra layer on the floodplain depended on the wind direction during the eruption. The air-fallen tephra was reworked by fluvial processes and deposited on the floodplain with decreasing sediment thickness downstream. After a phase of rapid adjustment of the fluvial system expressed by accumulation of mineral floodplain deposits, sediments with high (30-86\%) levels of organic matter mark a return to low sediment delivery to the floodplain. All in all, about $0.8 \mathrm{Mt}$ of post-eruption sediment was re-deposited by the river on the floodplain during the last 3,000 years.

Human impact on the fluvial system is only reflected in the middle reach where roads crossed the floodplain. The sediment production related to the road construction is in the order of $160 \mathrm{~kg} \mathrm{~m}^{-2}$ and thus comparable to the fluvial sediment deposition derived from volcanic eruptions. At other locations, however, no human-induced increase in sediment input was evident. We conclude from this that volcanic tephra deposition is the dominant forcing on sediment deposition in the Bibi River, despite society having achieved an advanced industrial level in the catchment.

\section{The Hokkaido perspective}

Many studies use paleoenvironmental records to assess the difference between present and past environmental conditions (Dearing at al. 2006). The quantification of background conditions, base lines or pre-impact references is difficult in very active geomorphic regions such as the Hidaka Mountains. The example from the Bibi River shows that volcanic forcing needs to be integrated with the effects of land use and climate change to understand the trajectory of fluvial systems.

Other impacts, not described in the two shown examples, include tsunamis, sea level change, and earthquakes. The recurrence interval of unusually large earthquakes and tsunamis along the Kuril subduction zone is about 365-553 years (Nanayama et al. 2007). In the past, such events impacted landscapes up to three kilometers inland, disturbing river regimes in the flat, lowest reaches. In addition, large earthquakes during the last 300 years raised the coastlines and the lowest reaches of rivers in eastern Hokkaido by about one meter. All these impacts and controls need to be taken into consideration when studying fluvial systems, not only in Hokkaido but also in other tectonically active regions.

\section{AFFILIATIONS}

${ }^{1}$ College of Geoscience, University of Tsukuba, Japan ${ }^{2}$ Graduate School of Agriculture, Hokkaido University, Sapporo, Japan

\section{CONTACT}

Thomas Parkner: parkner.thomas.gb@u.tsukuba.ac.jp REFERENCES

Dearing JA at al. (2006) Reg Environ Change 6: 1-16 Nanayama F et al. (2007) Sediment Geol 200: 275-294

Sawai Y et al. (2009) J Geophys Res Solid Earth 114, doi: 10.1029/2007JB005503

Shimizu O (1998) Res Bull Hokkaido Univ For 55: 123-215 Wasson RJ (1996) PAGES Report 96-2, 52 pp 